Revista de Comunicación y Salud, 2017, Vol. 7, pp. 173-186

Editado por Cátedra de Comunicación y Salud

ISSN: 2174-5323 (impreso) 2173-1675 (electrónico)

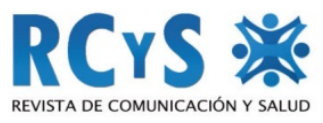

Enviado 28 de mayo de 2017

Aprobado 15 de julio 2017

\title{
ESTRATEGIA PARA LA OPTIMIZACIÓN DE LA COMUNICACIÓN DE RIESGO EN LA CRISIS DEL ÉBOLA
}

\section{Strategy for the optimization of risk communication in the ebola crisis}

Antonio González Pacanowski ${ }^{1}$, Pablo Medina Aguerrebere*, Mar Iglesias García

Universidad de Alicante. España

*Universidad de Ginebra. Suiza

\section{Resumen}

La propagación de enfermedades endémicas como el ébola en las sociedades desarrolladas ha planteado la revisión de los modos y estrategias de comunicación institucional, así como de la comunicación realizada por los medios de comunicación masiva. La experiencia obtenida en España puede ayudar a aclarar las claves del proceso de comunicación de riesgos. Tras una revisión bibliográfica y un estudio sobre la gestión comunicativa de la crisis del ébola en España, se propone un modelo de comunicación para reducir los riesgos en los trabajadores de la salud y mejorar la calidad de la información institucional. Esta investigación se enmarca dentro del Plan Nacional CSO2016-81882-REDT.

Palabras clave: Ébola; EVE; crisis de comunicación; infección; comunicación de riesgo; comunicación sanitaria

\begin{abstract}
The spread of endemic diseases such as Ebola in developed societies has raised the review of modes and strategies of corporate communication as well as communications of mass media. The experience obtained in Spain can help to clarify the keys of the risk communication process. After a literature review and a study about the strategies of communication in Spain during the Ebola crisis, we propose a communication model to reduce risks in health workers and to improve the quality of corporate information. This research is part of the National Plan CSO2016-81882-REDT.
\end{abstract}

Key words: Ebola; EVE; communication crisis; infection; risk communication; health communication.

\section{Para citar el artículo}

González Pacanowski, A.; Medina Aguerrebere, P.; Iglesias García, M. (2017). Estrategia para la optimización de la comunicación de riesgo en la crisis del Ébola. Revista de Comunicación y Salud, vol. 7, 173-186. Recuperado de http://revistadecomunicacionysalud.org/index.php/rcys/article/view/123

\footnotetext{
${ }^{1}$ Autor de contacto: toni.gonzalez@ua.es
} 


\section{INTRODUCCIÓN}

Cuando la opinión pública refleja un estado de opinión, en ocasiones el origen del mismo se puede encontrar en un proceso de comunicación transferido del ámbito interno organizacional al externo. Esta transferencia de información produce una tensión motivada por la polaridad conceptual entre lo confidencial y lo público. Toda la información privada interna de una organización ha de ser, o debería tender a ser comprensible y descodificable por sus públicos específicos. Sin embargo, cuando se hace pública sin planificación en situaciones críticas o de emergencia, alcanza a destinatarios ajenos muy distantes de la organización y su cultura. Pierde entonces la contextualización y, evidentemente, no es posible para los receptores ajenos establecer una conexión con todo el conocimiento de la estructura de la organización y sus peculiaridades. La desaparición del carácter confidencial o privado implica la anulación de información clave en dicha transferencia. Es lo que denominamos una "deconstrucción" del modelo comunicativo organizacional a causa de la crisis.

Los procesos de comunicación permiten a la organización mantener la coordinación entre sus distintas partes y alcanzar así su característica esencial: ser un sistema. Sin embargo, el tradicional sistema abierto de Katz y Khan (1989), utilizado para comprender la funcionalidad de las organizaciones y sus elementos en la psicología de éstas, se desestabiliza cuando se producen las crisis de comunicación. La organización se enriquece de sus propias crisis, pero en ocasiones puede que dicha deconstrucción provocada por éstas alcance a otras organizaciones relacionadas $\mathrm{o}$ ajenas. Los roles interrelacionados y las competencias comunicacionales de cada uno de sus miembros se emborronan con la urgencia y la precipitación que provocan las crisis de comunicación.

Las organizaciones funcionales son ya un modelo aceptado, pero en cualquier caso se trata de estructuras complejas, como referenciaron en su día Katz y Khan. Según ambos, en las organizaciones cada individuo integra sus relaciones y conductas mediante un puesto, de modo que configura un punto particular del espacio organizacional. Este espacio, a su vez, se enmarca en una estructura de puestos interrelacionados y a una pauta de actividades asociadas con ellos. Cada puesto tiene una actividad y conductas esperadas (Katz \& Khan, 1989).

En organizaciones complejas, como las hospitalarias, es imprescindible disponer de un plan estratégico ante las crisis de salud si se pretende una actividad y conducta esperada. En el caso de la Enfermedad del Virus de Ébola (EVE) con pacientes del grupo 4 resulta crucial tener en cuenta el asesoramiento científico, pasando por las estructuras de enlace, mando y la gestión de la información y de las comunicaciones en situaciones críticas. Una implicación que ha de ser global, abarcando al conjunto de los profesionales tanto de la atención urgente, como la emergente. De esta forma, es posible eludir errores, mejorándose la credibilidad. Ello afecta especialmente a los responsables de la gestión de la comunicación institucional. (Moreno Millán, 2008).

La crisis del Ébola, cuyo origen (Sáez et al, 2014) y, por otro lado, sus trayectorias epidemiológicas son evidentes (Baize et al, 2014), se ha investigado 
desde diferentes puntos de vista de la teoría de la comunicación. Se trataba de una crisis diferente a la pandemia de gripe $\mathrm{A}(\mathrm{H} 1 \mathrm{~N} 1)$ en el año 2009 y el brote de E.Coli entero hemorrágico, notificado en Alemania en 2011, ambos con elevadas cifras de fallecidos. Igualmente es diferente a la contaminación en el síndrome tóxico (año 1981); o el denominado vulgarmente "vacas locas" (año 2000). La epidemia por EVE tiene hoy claros sus protocolos de actuación por parte del ministerio de Sanidad de España, incluso para profesionales no sanitarios ${ }^{2}$. También el uso de materiales más adecuados y eficaces para proteger y mejorar la acción de los profesionales sanitarios (Cique, 2015) ha sido uno de los temas cruciales, dado el debate generado en torno a la necesidad de optimizar la protección personal.

Desde el punto de vista de la investigación en prevención de riesgos laborales en el mundo sanitario, recientemente se ha abordado su praxis donde caben destacar estudios varios (Fernández, 2015; Herrero et al, 2015). También otras revisiones han presentado la innovación tecnológica en redes sociales y apps, así como la crítica por la tardanza de la respuesta gubernamental en este aspecto (Quesada, 2014).

La relevancia informativa de la crisis del EVE en España se ha producido en una etapa en la que el interés social en la información sanitaria tiende al alza. Asistimos en dicho contexto a una segmentación de nuevas audiencias cuyas expectativas informativas no son las mismas que las de los públicos internos habituales de la organización. Sin embargo, la preocupación por las consecuencias de un contagio como podría ser el mismo Ébola u otras infecciones, no parecen aparentemente estar entre los problemas de salud de interés para la sociedad española si nos atenemos a las estadísticas.

En cualquier caso, resulta evidente que las informaciones de salud en los medios de comunicación ofrecen temas prioritarios de interés para la población (Centro de Investigaciones Sociológicas, 2011). Se busca la mejora de la calidad de vida, respuesta a las enfermedades, tratamientos, patologías e investigación, entre otros temas. Una necesidad de priorizar que exige lazos más estrechos entre ámbitos profesionales como son el de la salud y la comunicación, como señala el estudio del equipo de Peñafiel et al. (2014). En su análisis, la información de salud carece de perspectiva educativa. Propone la especialización profesional y la mejora de relación entre médicos y periodistas.

El escenario actual implica igualmente una necesidad de atender las demandas del paciente "empoderado", cuyo perfil muestra necesidades informativas y capacidad de movilización diferente a la etapa en que donde el desarrollo de internet no se había producido (ONTSI, 2016). El Observatorio Nacional de las Telecomunicaciones y de la Sociedad de la Información destaca en este sentido que uno de cada cuatro ciudadanos usa las redes sociales para cuestiones de salud.

\footnotetext{
${ }^{2}$ Protocolo de actuación ante una aero evacuación médica ante casos de enfermedad por virus del ébola". Ver en: http://www.msssi.gob.es/profesionales/saludPublica/ccayes/alertasActual/ebola/docs/Protocolo_ae roevacuacion_05092014.pdf. "Información general sobre ébola. Documento de apoyo para profesionales del sector no sanitario". Ver en http://www.msssi.gob.es/profesionales/saludPublica/ccayes/alertasActual/ebola/documentos/EBOL Asectornosanitario14.01.2015.pdf
} 
Sin duda, la mejor fórmula que optimizaría la comunicación en situaciones de brotes epidémicos, como es el ébola, es la preparación previa para la toma de decisiones rápidas y en circunstancias de presión social e informativa (Quiral, 2015).

\section{ANÁLISIS COMUNICACIONAL}

La identificación clara del foco, el ámbito internacional y la preocupación por los efectos potenciales letales han llevado a distintos análisis comunicacionales, como se ha comentado. Algunas recomendaciones tras la crisis de comunicación evaluando la praxis institucional (Jurado \& Jurado, 2015) se han concretado de la forma siguiente: a) ofrecer toda la información disponible con transparencia y veracidad, b) Designar portavoces expertos y adecuados, c) evitar rumores y mensajes contradictorios que generen alarmismo y d) respetar la intimidad de los afectados, de su familia y de su entorno.

En otro sentido, se ha indicado que los medios de comunicación desempeñan un papel importante en la percepción del riesgo social en temas como el Ébola y Enfermedades Raras. Las noticias sobre la propagación y las consecuencias fatales de Ébola llevan a que se considere como una enfermedad de "riesgo terrible", mientras que las noticias sobre otras enfermedades raras y el daño que pueden causar las definen como de "riesgo desconocido" (Carretón \& Villafranca, 2016). Otros autores han sido críticos con la gestión institucional de la comunicación sobre el contagio del Ébola, en referencia a las acciones del ministerio de Sanidad español. En este sentido, se le atribuye falta de coordinación y especialmente la inhibición al no identificar las responsabilidades de las personas competentes en la detección del contagio (Micaletto \& Gallardo, 2015).

Respecto a las redes sociales y tomando como referencia el análisis elaborado sobre el medio El País (Costa, Rodríguez \& López, 2015), tanto por los comentarios generados como por las ratios de redifusión en redes sociales, fue evidente el rol activo de los usuarios utilizando canales y plataformas de la organización empresarial periodística. Es decir, los medios, como es el caso de El País, generaron a su vez una actividad en las diferentes redes sociales, donde especialmente preocupó el problema del riesgo laboral vinculado a la protección de los trajes empleados por el personal asistencial.

La conveniencia de promover campañas con el apoyo de redes sociales y medios de comunicación en canales electrónicos como CNN, Yahoo o Reuters se ha propuesto asimismo como vía de actuación, vista la eficacia de la red social Twitter (Househ, 2016). Incluso, su utilidad como sistema de vigilancia en fases tempranas (Odlum \& Yoon, 2015). Sin embargo, el inconveniente, en el caso de Twitter, es la inexistencia de garantías sobre la veracidad de la información relacionada con el Ébola (Oyeyemi, Gabarron, \& Wynn, 2014).

Por otro lado, la opinión pública testada a posteriori de la crisis en la Comunidad Autónoma de Madrid, lugar donde se enmarca esta crisis, mostró que existe una mayoría de la población que confía en la eficacia del sistema sanitario 
público (GAD3, 2004) y, al mismo tiempo, una proporción significativa que describe como alarmante la información difundida por los medios (ver figura 2). Ello supone, pese a que los recursos sanitarios sean avanzados, nada evitará que se genere preocupación social (Europa Press, 2014). Las conclusiones de la encuesta de GAD3 fueron interesantes para los efectos en la opinión pública. El $26 \%$ afirmaba estar preocupado por un posible contagio del virus. Un $73 \%$ tenía mucha o bastante confianza en que el sistema sanitario español fuese capaz de controlar una epidemia de Ébola. En el caso de nuevos contagios de españoles en África, un $47 \%$ se mostraba partidario de traerlos a España para intentar curarles, frente al 38\% que se inclina por dejarle en ese país, para evitar contagios. Los entrevistados, y es un aspecto preventivo curioso, son más partidarios de combatir el Ébola en África con el envío de alimentos y medicinas, que con el envío de militares españoles: un $96 \%$ frente al $73 \%$. La credibilidad también fue testada. Un $59 \%$ consideraba mucho o bastante creíble la información emitida por los portavoces sanitarios, responsables de la comunicación de la gestión del Ébola. Para la mayoría, la imagen de la Sanidad Pública española se había mantenido igual, según reflejaba un $53 \%$ de los entrevistados, frente a un $24 \%$ que consideraba que había mejorado tras la crisis del Ébola. Respecto a la información de los medios de comunicación sobre el contagio, fue valorada como comprensible por un $61 \%$, alarmante en un $56 \%$ y rápida en un 51\%. En contraste, un $46 \%$ la consideró poco rigurosa. Curiosamente se producía un disenso sobre la cantidad de información: un $37 \%$ la calificó como excesiva mientras un $37 \%$ la definió como insuficiente. (Ver figura uno).

La falta de rigor es sin duda un hecho destacable según la opinión testada.
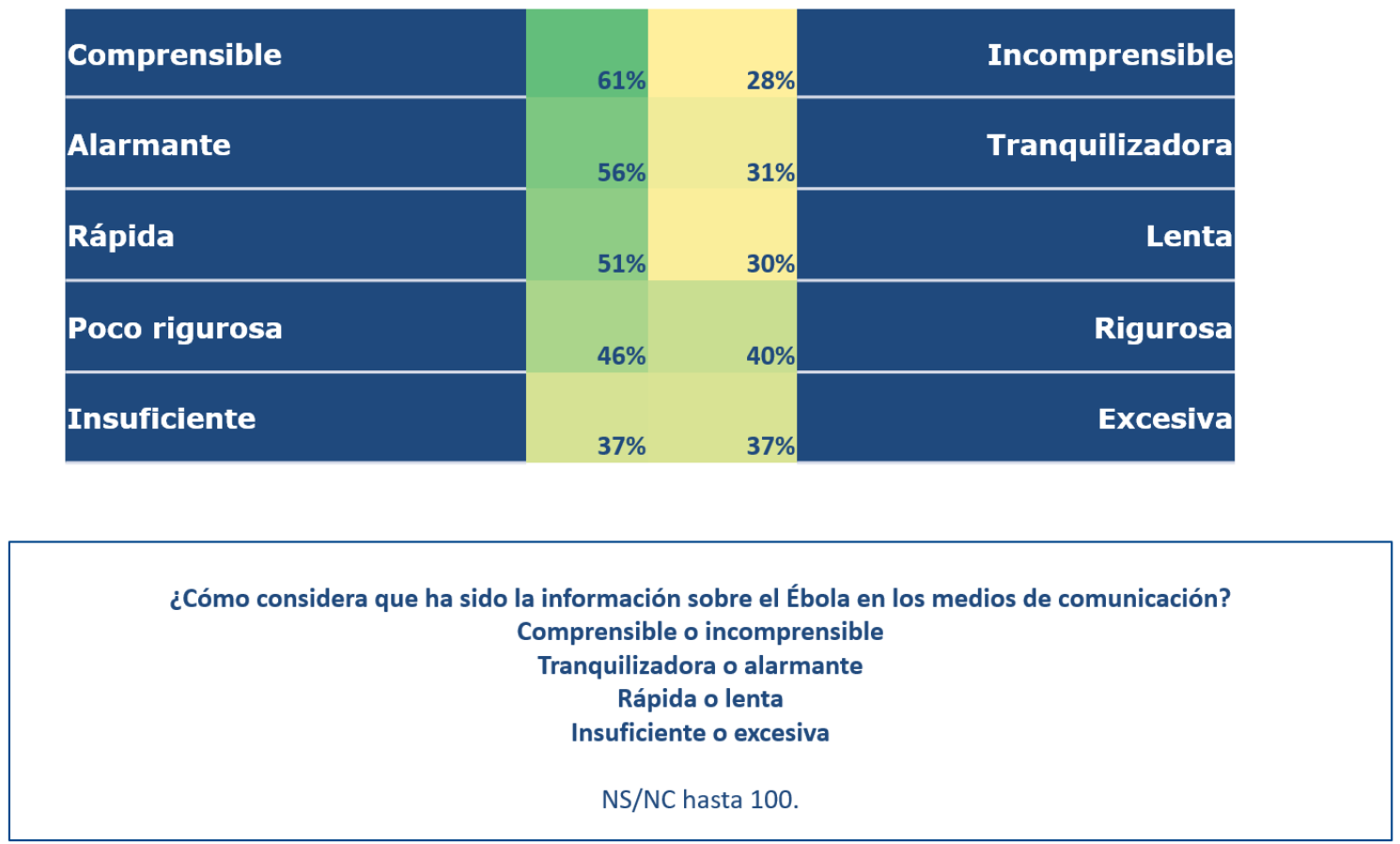

Figura 1: Valoración de Información en los medios.

Fuente: GAD3. 2004. 


\section{CRONOLOGÍA DE LA CRISIS}

El caso de la crisis del Ébola en España se inicia informativamente con el compromiso del Gobierno español de repatriar un voluntario afectado en el mes de agosto del año 2014 (Prats, 2014; Portalatín, 2014). Su fallecimiento posterior, único caso de mortalidad por la infección en España, conlleva el contagio de una profesional sanitaria en octubre de 2014, que, tras meses de convalecencia, se recupera. En el transcurso de su recuperación suceden algunos hechos que adquieren relevancia social como el sacrificio de "Excalibur", el perro de la afectada y de su pareja.

En este proceso pueden establecerse dos fases diferenciadas. Por un lado, desde que se inicia la infección en el foco de origen donde los voluntarios españoles precisan retornar a España y se produce la repatriación del médico español enfermo que, como se ha indicado, posteriormente fallecería. La segunda fase en la que tiene lugar el contagio de la enfermera voluntaria, es la que provoca la crisis estricta. El análisis de los contenidos difundidos en medios de comunicación hace pensar que la psicología colectiva reflejaba de modo latente los siguientes elementos:

1. Sensación de que el contagio puede propagarse con facilidad entre los habitantes.

2. Apariencia de que el sistema sanitario público es defectuoso para situaciones de máxima seguridad terapéutica.

3. Desconocimiento entre la población de las instalaciones y recursos sanitarios específicos.

4. Ausencia de información preventiva y educación sanitaria accesible para los ciudadanos para circunstancias críticas.

5. Desprotección de los profesionales sanitarios en la realización de su trabajo en circunstancias de máximo riesgo para ellos y la población.

En esta fase de crisis podemos identificar dos sub-crisis asociadas, por un lado, la que se genera por el sacrificio del perro "Excalibur", donde entran en juego asociaciones protectoras de animales y movilizaciones, y la segunda subcrisis que recoge el cúmulo de críticas que recibe el Ministerio de Sanidad y que desde organizaciones políticas se traducirá en la petición de dimisión de la propia ministra en ese momento, Ana Mato (Ver anexo 1: cronología de titulares).

El comienzo de la crisis estricta del Ébola se da en el ámbito de la práctica profesional de la enfermería. Es una cuestión relacionada en primer término con los sistemas de información en la prevención de riesgos laborales. Un fallo en las medidas profilácticas de atención al paciente y una exposición a la enfermedad en un escenario de máximo riesgo de contagio suponen después un tratamiento en aislamiento. El interés mediático y las informaciones que se difundirán son posteriores, creándose un clima de opinión que cuestiona, desconfía y en consecuencia compromete a las autoridades sanitarias.

Hasta la fecha de la crisis, la formación del personal sanitario, tanto de médicos como enfermeras, para la prevención de contagio de enfermedad como el Ébola en centros sanitarios era un aspecto desconocido para la mayor parte de la 
profesión. Se impartía únicamente en determinadas especialidades donde la exposición es evidente, como en atención de urgencias y catástrofes, así como en centros de investigación donde se requiere obligatoriamente para el trabajo diario. La legislación española establece que cada empresa y en función de su organización interna deberá establecer su propio circuito de comunicaciones de manera que se asegure un seguimiento y un control del sistema en la prevención de riesgos laborales. El proceso que inicia el comunicante llega a la dirección del centro u organización y requiere una doble vía de circulación, mediante comunicación escrita y copia (Ver figura dos).
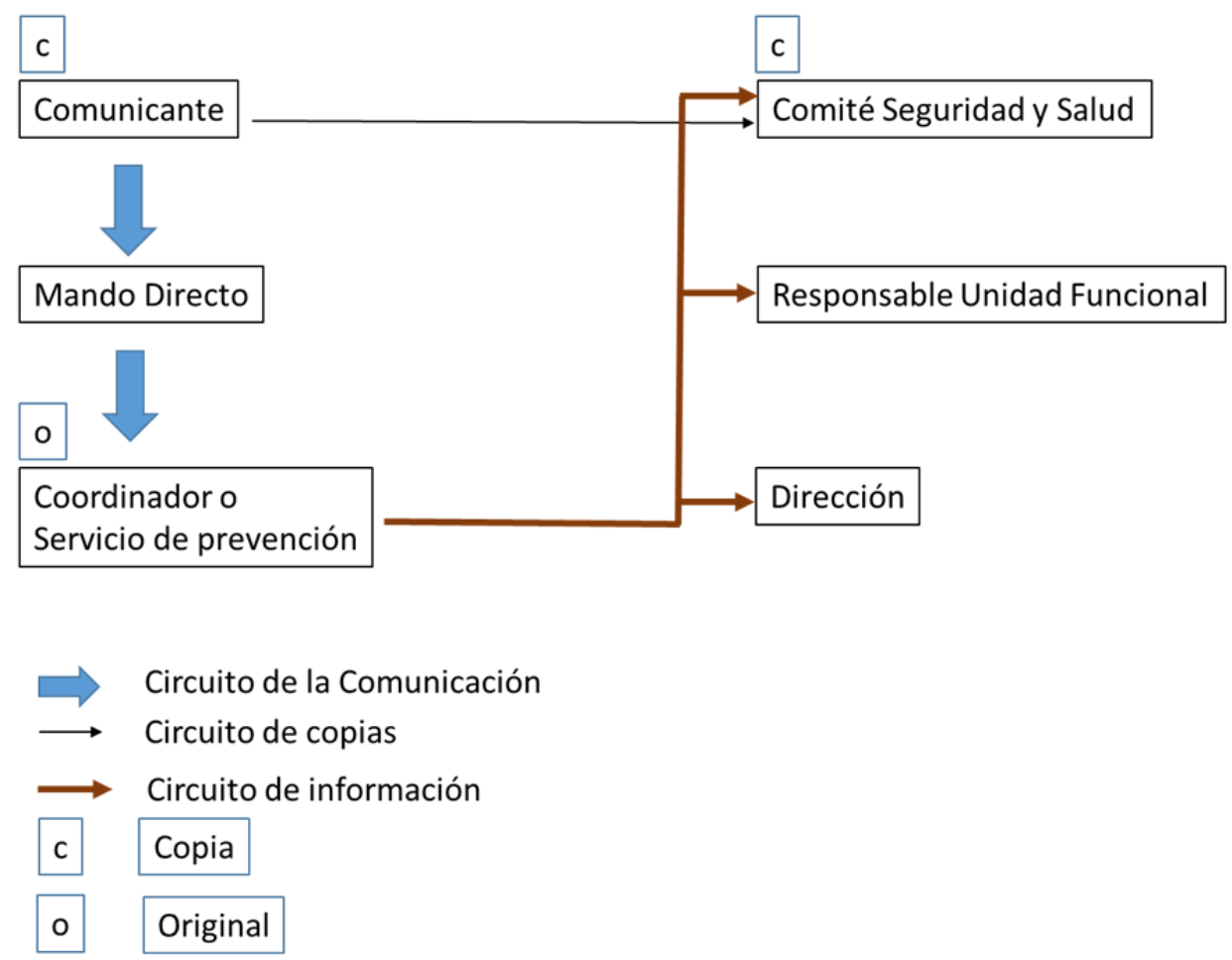

Figura 2: Proceso de comunicación y circuito informativo en la Ley de Prevención de Riesgos Laborales.

Resulta evidente que este proceso supone la interacción de varias partes, al mismo tiempo que se establecen los controles oportunos. Por todo ello, la comunicación de riesgo para la salud "es la manera en que nos comunicamos con varias partes interesadas sobre la naturaleza y el nivel de riesgo, así como los controles que podemos tomar para reducir ese riesgo" (ATSDR, 2001). Pero es preciso tener claras las diferencias. Los riesgos que matan a las personas y los riesgos que las alarman son totalmente diferentes (Covello \& Sandman, 2001).

Esta es la diferenciación que debe estar en la base de la comunicación de los mensajes preventivos ante un riesgo laboral de alta severidad, como es un contagio que pueda comprometer la supervivencia de una persona. En el ámbito de la comunicación interna de las organizaciones los contenidos de los mensajes compiten entre sí y se perciben en categorías diferentes por los receptores. De ahí que tratándose de un riesgo de contagio que puede ser mortal, resulta más necesario si cabe priorizarlos y diferenciarlos en el plan de prevención de riesgos 
laborales. Pese a la formación, competencia y responsabilidad demostrada se produjo dicho contagio en el trabajador. El proceso de comunicación, al menos en términos de eficacia puede ser discutible, pero no se puede atribuir negligencia o descuido alguno a la actuación, tanto de la propia enfermera afectada, como del resto del equipo que la atendió en las semanas posteriores.

La Ley de Prevención de Riesgos Laborales 31/1995, del Ministerio de Trabajo (1995), en su artículo 15 "Principios de la Acción Preventiva" y en su artículo 29, apartado $4^{\circ}$, señala claramente las responsabilidades del trabajador: "Informar de inmediato a su superior jerárquico directo, y a los trabajadores designados para realizar actividades de protección y de prevención o, en su caso, al servicio de prevención, acerca de cualquier situación que, a su juicio, entrañe, por motivos razonables, un riesgo para la seguridad y salud de los trabajadores" (Ley Prevención Riesgos Laborales, 1995). Según la ley, cada trabajador debe conocer los riesgos que le afectan, las medidas adoptadas para evitarlos para poder informar rápidamente de ellos. Para identificar riesgos no evaluados o no evitados y elaborar nuevas propuestas preventivas, se establece el Procedimiento de Comunicación de Riesgos que es un instrumento de Participación y Evaluación Continua. Por otra parte, la Ley de Prevención 31/1995 señala que la Administración, como empleador, adoptará medidas para que sus trabajadores reciban información en relación con los riesgos para su seguridad y salud laboral, las medidas de prevención aplicables y las adoptadas para emergencia. ¿Existía en el caso del contagio por EVE la información suficiente $y$, sobre todo, canalizada correctamente en el momento preciso?

Queda para la discusión hasta qué punto un profesional expuesto a un riesgo de contagio como es el virus del Ébola debe ser ingresado y tratado con medidas preventivas adecuadas ante cualquier mínimo síntoma. El diario El País en su información de la cronología, informó que la profesional enfermera no se declaró como paciente de riesgo en el ambulatorio, y fue atendida posteriormente con fiebre elevada por equipos sanitarios no especializados, antes de su aislamiento final para ser tratada por EVE (Pérez Barredo, 2014).

\section{PROPUESTA Y CONCLUSIÓN}

La fase de incubación de la enfermedad diluye la posibilidad de la comunicación inmediata en el proceso habitual establecido por la normativa española. Al mismo tiempo, cualquier profesional sanitario en contacto con pacientes contagiados, y que comunique el más mínimo síntoma, debería considerarse ser aislado y permanecer en observación monitorizada el tiempo necesario para descartar o tratar cualquier infección. Sin embargo, este extremo es discutible y deberían sopesarse quizá en función del caso y el nivel de riesgo de contagio. Respecto a los desplazados a zonas de riesgo, ante el conocimiento de la exposición por parte del afectado, sería precisa una información previa a los servicios de prevención de riesgos laborales. Hoy no es obligatorio informar a los servicios de prevención antes de iniciar cualquier asistencia o viaje a lugares con brotes víricos contagiosos reconocidos. Una vez que se ha retornado del país o lugar donde existe el brote endémico declarado, el seguimiento sería específico y 
diferenciado respecto de otros casos en los que los itinerarios no entrañaran posibilidades de contagio.

A modo de recomendación, se establece el siguiente modelo comunicativo como posible referencia para su posterior adaptación organizacional.

1. Diseño del plan de comunicación específico para casos de contagio de enfermedad infecciosa grave y de alta severidad. Dicho plan se activaría en el momento que una persona se desplaza a territorios problemáticos y tendría dos fases de seguimiento, una preventiva y otra terapéutica, ésta segunda si fuera necesaria la intervención clínica.

1.1 Diseño de canales internos para la comunicación ascendente y descendente de la organización. Integración de Dirección, Unidad Funcional y Comité de Seguridad y Salud. Al tratarse de una información donde las decisiones tienen que ser rápidas y consensuadas, es conveniente que los receptores con capacidad de decisión puedan aportar su feedback del modo más ágil posible, por lo que precisan todos los datos desde el primer momento.

1.2 Definición de portavoces autorizados, mensajes clave para su difusión y formación de dichos portavoces autorizados. La complejidad de este tipo de enfermedades y su tratamiento exige una actualización de la formación de los portavoces y las normas claras para evitar alarmismo o preocupación social innecesaria.

2. Diseño del plan de formación específico para personal expuesto, integrado en los canales de información al personal sanitario. Todos los trabajadores sanitarios relacionados deben tener su argumentario claro sobre la enfermedad en función de sus competencias, y no confundir a otros profesionales o personas no expertas.

3. Actualización permanente de los contenidos informativos y formativos dirigidos al público general y especialmente a colectivos de riesgo que puedan tener contacto o haberlo tenido con la enfermedad. El público general que se desplaza, y especialmente los cooperantes son un target en esta tarea informativa que ha de estar al día.

4. Diseño de contenidos, canales y soportes en tecnologías móviles y digitales para su uso por profesionales y grupos de riesgo afectados. Es preciso diseñar herramientas con tecnologías de comunicación eficientes para lograr el efecto deseado.

5. Workflow específico funcional: Se propone un modelo donde la información del contagio del afectado se activa previamente antes de cualquier exposición, con un doble proceso de comunicación en dirección horizontal entre departamentos y feedback de confirmación, así como un tercer "proceso de actuación urgente" (código cero) autónomo, coordinado con los recursos organizativos. Los tres procesos son simultáneos, pero el que permite la actuación correctora para el contagiado por el virus es 
discrecional y activa un "proceso de actuación urgente". Ante el conocimiento de contacto con el virus, los servicios de prevención deben activar el proceso de actuación urgente aislando al afectado y confirmando la infección, y evitar así la incertidumbre de la fase de incubación de virus (Ver figura tres).

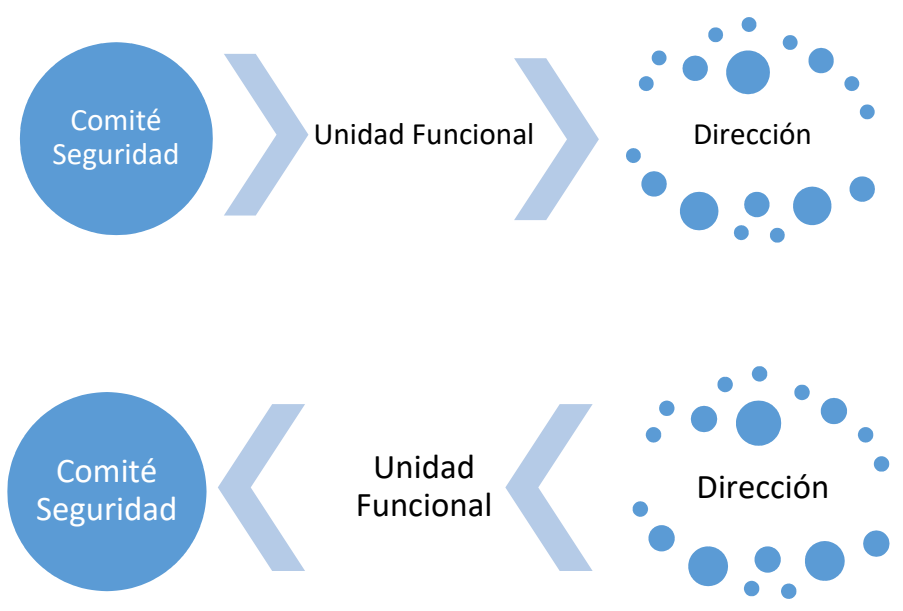

Código Cero: proceso de actuación urgente

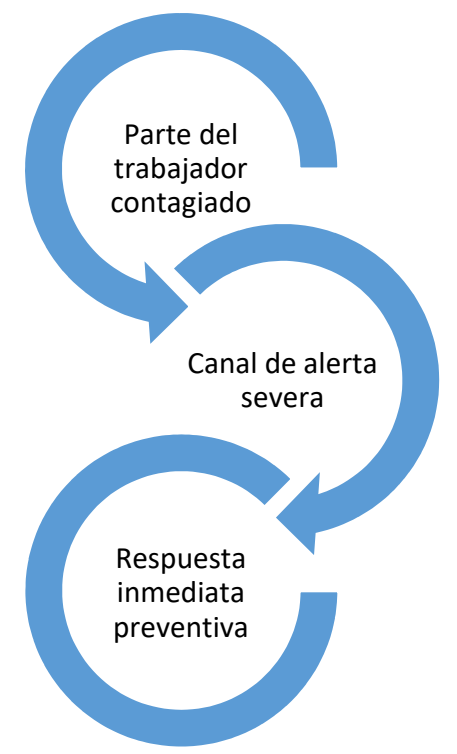

Figura 3. Activación en modelo horizontal con feedback y código cero

\section{REFERENCIAS}

ATSDR (2001). Tools and Techniques for Effective Health Risk Communication Agency for Toxic Substances and Disease Registry (ATSDR). Washington: U.S. Department of Health and Human Services. 
Baize, S.; Pannetier, D.; Pharm. D.; Oestereich, L; Rieger, T.; Koivogui, L.; ... Günther, S. (2014). Emergence of Zaire Ebola Virus Disease in Guinea. New England Journal of Medicine, 371, 1418-1425. doi: 10.1056/NEJMoa1404505.

Centro de Investigaciones Sociológicas (2011). Barómetro sanitario, 2011. Resultados totales de las tres oleadas. Estudios $n^{\circ} 2.862,2.906$ y 2.916 . Madrid: Centro de Investigaciones Sociológicas.

Carretón, C. \& Villafranca, P. (2016). The impact of the Ebola Virus and rare diseases in the media and the perception of risk in Spain. Catalan Journal of Communication \& Cultural Studies, 8(2), 245-263. doi:https://doi.org/10.1386/cjcs.8.2.245_1.

Cique, A. (2015). Evacuación de pacientes con sospecha o confirmación de enfermedad por el virus del Ébola. Revista Emergencias, 27(2), 121-128.

Costa, C.; Rodríguez, A. \& López, X. (2015). Del periodismo transmedia al replicante. Cobertura informativa del contagio de ébola en España por Elpais.com. El profesional de la información, 24(3), 282-290. doi:http://dx.doi.org/10.3145/epi.2015.may.08.

Covello. V, \& Sandman, M. (2001). Risk communication: Evolution and Revolution. En A. Wolbarst (Ed), Solutions for an Environment in Peril (pp. 164-178). Baltimore: The Johns Hopkins University Press.

Europa Press (2014). Casi la mitad de los madrileños serían partidarios de repatriar a nuevos contagiados por el virus en África. Recuperado de http://www.europapress.es/nacional/noticia-casi-mitad-madrilenos-serianpartidarios-repatriar-nuevos-contagiados-virus-africa-20141030185036.html.

Fernández, M. V. (2015). Protección personal con casos confirmados de enfermedad por virus Ébola. Adaptación a una Unidad de Aislamiento de Alto Nivel (UAAN). IX Congreso Nacional de los Servicios de Prevención de Riesgos Laborales en el Ámbito Sanitario. Madrid, Hospital Universitario 12 de Octubre.

GAD3 (2014). Percepción social sobre la crisis del virus Ébola. Recuperado de http://www.gad3.com/es/noticias\#/percepcion-social-sobre-la-la-crisis-delebola.

Herrero, J.; Moriel, R.; Herrero, S.; Moltó A.R. \& Herrero, E. (2015, febrero). Equipos de Protección Individual en situaciones de alto riesgo de exposición a virus Ébola. IX Congreso Nacional de los Servicios de Prevención de Riesgos Laborales en el Ámbito Sanitario. Madrid, Hospital Universitario 12 de Octubre.

Househ, M. (2016). Communicating Ebola through social media and electronic news media outlets: A cross-sectional study. Health informatics journal, 22(3), 470-478.

Jurado, E. \& Jurado, M. (2015). Errores de comunicación en la crisis del Ébola. Recuperado de http://www.cuadernosdeperiodistas.com/los-errores-decomunicacion-en-la-crisis-del-ebola.

Katz, D. \& Kahn, R. (1989). Psicología social de las organizaciones. México: Trillas.

Ministerio de Trabajo (1995). Ley de Prevención de Riesgos Laborales 31/1995. Recuperado de http://noticias.juridicas.com/base_datos/Laboral//311995.html 
Micaletto, J.P. \& Gallardo, L. (2015). La comunicación institucional en la crisis del ébola en Europa: el caso de la crisis española de 2014 en sus inicios. Revista Internacional de Relaciones Públicas, 9, 89-110. http://dx.doi.org/10.5783/RIRP-9-2015-06-89-110.

Moreno Millán, E. (2008). Gestión de la información y la comunicación en emergencias, desastres y crisis sanitarias. Revista de la Sociedad Española de Medicina de Urgencias y Emergencias, 20(2), 117-124.

ONTSI (2016). Los ciudadanos ante la e-Sanidad. Opiniones y expectativas sobre el uso y aplicación de las TIC en el ámbito sanitario. Recuperado de http://www.ontsi.red.es/ontsi/sites/ontsi/files/los_ciudadanos_ante_la_esanidad.pdf.

Oyeyemi, S. O., Gabarron, E., \& Wynn, R. (2014). Ebola, Twitter, and misinformation: a dangerous combination?. Bmj, 349, g6178.

Odlum, M., \& Yoon, S. (2015). What can we learn about the Ebola outbreak from tweets?. American journal of infection control, 43(6), 563-571.

Peñafiel, C.; Camacho I.; Aiestaran, A.; Ronco, M. \& Echegaray, L. (2014). La divulgación de la información de salud: un reto de confianza entre los diferentes sectores implicados. Revista Latina de Comunicación Social, 69, 135-151. doi: 10.4185/RLCS-2014-1005.

Pérez Barredo, A. (2014, 8 octubre). Los últimos pasos de la sanitaria contagiada antes de su aislamiento. El País. Recuperado de http://politica.elpais.com/politica/2014/10/07/actualidad/1412675565_479466. html.

Portalatín, B. (2014, 9 octubre). Cronología del Ébola en España. El mundo. Recuperado

de http://www.elmundo.es/salud/2014/10/09/5436be10ca4741d0438b4592.html.

Prats, J. (2014, 6 agosto). España se dispone a repatriar al sacerdote infectado de Ébola. El País. Recuperado de http://sociedad.elpais.com/sociedad/2014/08/05/actualidad/1407227683_136 407.html

Quesada, V. J. (2014). Ébola y nuevas tecnologías. Cuadernos de Atención Primaria, 20, 210-211.

Quiral (2015). La comunicación pública sobre la enfermedad del Ébola. En Informe Quiral 2014 Medicina, comunicación y sociedad (pp. 55). Barcelona: Fundació Vila Casas y Observatorio de la Comunicación Científica de la Universidad Pompeu Fabra Recuperado de http://www.fundaciovilacasas.com/es/salud-iinforme-quiral/_year:2015/.

Sáez, A.; Marí, A.; Weiss, S.; Nowak, K.; Lapeyre, V.; Zimmermann, F.; ... Leendertz, F. (2014). Investigating the zoonotic origin of the West African Ebola epidemic. EMBO Molecular Medicine, 30, 7(1), 17-23. doi 10.15252/emmm.201404792.

\section{ANEXOS}

\section{Anexo 1. Cronología de titulares}

\section{6 de octubre}

- Primeras noticias:

http://www.bolsamania.com/noticias/pulsos/ana-mato-convoca-a-ungabinete-de-crisis-por-el-primer-contagio-de-ebola-en-espana--604773.html 
Estrategia para la optimización de la comunicación de riesgo en la crisis del Ébola

- Rueda de prensa de la ministra Ana Mato: https://www.youtube.com/watch?v=GHjHpLFTWAo

\section{7 y 8 de octubre}

- Notas de prensa en web Moncloa y Ministerio de Sanidad http://www.lamoncloa.gob.es/serviciosdeprensa/notasprensa/msssi/Pagina s/2014/081014coninterterritorial.aspx; http://www.msssi.gob.es/gabinete/notasPrensa.do?id=3428.

9 de octubre

- Rajoy interviene desde Milán avalando a Mato: http://www.prnoticias.com/index.php/salud/1246-crisis-del-ebola/20134682rajoy-toma-las-riendas-de-la-crisis-de-comunicacion-del-ebola

- La Comisión Europea pide explicaciones a España: http://www.antena3.com/noticias/espana/pide-explicaciones-espanacontagio-ebola_2014100700089.html

\section{0 de octubre}

- Consejo de Ministros para creación del comité de expertos y comité interdepartamental. Rajoy y el presidente de la Comunidad de Madrid acuden al Hospital Carlos III: http://politica.elpais.com/politica/2014/10/10/actualidad/1412942978_06459 4.html; http://politica.elpais.com/politica/2014/10/09/actualidad/1412872730_98967 4.html.

\section{1 de octubre}

- Segundo caso de Ébola en Estados Unidos. Resumen de rueda de prensa: http://www.noticiasmundofox.com/noticias/autoridades-sanitarias-de-eeuuaseguran-que-incumplimiento-de-protocolos-habria-sido-la

- Portavoces expertos: http://noticias.lainformacion.com/espana/el-gobiernoencuentra-a-su-mejor-comunicador-en-la-crisis-delebola_Iv5JZtB2ORIryvxx6qnRe5/

\section{3 de octubre}

- $2^{a}$ Rueda de prensa de la Ministra Ana Mato: http://nataliasara.com/2014/10/13/el-titanic-de-la-comunicacion-sanitariade-crisis-por-el-ebola/

- Marido auxiliar, carta y respuesta del Consejero de Sanidad: http://www.antena3.com/noticias/sociedad/fernando-simon-teresa-romeropunto-critico-hoy-manana_2014101300054.html

\section{4 de octubre}

- Estados Unidos enviará equipos de respuesta rápida ante casos de Ébola: http://internacional.elpais.com/internacional/2014/10/14/actualidad/1413319 499_195090.html

- Mensaje de la enfermera: http://www.texashealth.org/newsalert.cfm? $\mathrm{id}=1629$ \&action $=$ detail $\&$ ref $=1890$ 


\section{5 de octubre}

- Tercer caso de Ébola; segundo contagio en Estados Unidos. Comparecencia Congreso Ana Mato: http://www.rtve.es/alacarta/videos/telediario/mato-admite-no-todo-sehecho-bien-crisis-del-ebola-tras-criticas-oposicion/2810400/

\section{6 de octubre}

- Obama cancela sus viajes para hacer frente a la crisis por Ébola en EEUU: http://politica.elpais.com/politica/2014/10/16/actualidad/1413483873_98754 7.html

\section{7 de octubre}

- Rueda de prensa de Vicepresidenta tras Consejo de Ministros: http://www.lamoncloa.gob.es/consejodeministros/resumenes/Paginas/2014/ 171014-consejo.aspx?galv2r=1

\section{8 de octubre}

- En EEUU llueven críticas contra CDC y Obama decide nombrar a un superencargado:

http://www.eleconomista.es/internacional/noticias/6168479/10/14/Obamanames-Ebola-czar-beefs-up-Texas-response.html 